\title{
Novel reversibly switchable wettability of superhydrophobic-superhydrophilic surfaces induced by charge injection and heating
}

\author{
Xiangdong $\mathrm{Ye}^{\star} \S$, Junwen Hou and Dongbao Cai
}

\author{
Full Research Paper \\ Address: \\ School of Mechanical and Electrical Engineering, Shaanxi Key \\ Laboratory of Nano Materials and Technology, Xi'an University of \\ Architecture and Technology, Xi'an 710055, China \\ Email: \\ Xiangdong Ye* - yexiangd@xauat.edu.cn \\ * Corresponding author \\ § Tel: 86-029-82202553, Fax: 86-029-82202552 \\ Keywords: \\ charge injection; heating; reversible wettability; superhydrophilic; \\ superhydrophobic
}

\author{
Beilstein J. Nanotechnol. 2019, 10, 840-847 \\ doi:10.3762/bjnano.10.84 \\ Received: 28 November 2018 \\ Accepted: 14 March 2019 \\ Published: 10 April 2019 \\ Associate Editor: E. Meyer \\ (c) 2019 Ye et al.; licensee Beilstein-Institut. \\ License and terms: see end of document.
}

\begin{abstract}
Reversibly switching wettability between superhydrophobicity and superhydrophilicity has attracted widespread interest because of its important applications. In this work, we propose a reversible superhydrophobic-superhydrophilic conversion induced by charge injection and heating. Different from the conventional electrowetting phenomenon caused by the accumulation of solid-liquid interfacial charges, we discovered a phenomenon where charge injection and accumulation at the solid surface results in a sharp increase in wettability. The wettability of a sprayed $\mathrm{SiO}_{2}$ nanoparticle coating on a glass slide was shown to change from superhydrophobic to superhydrophilic by charge injection and heating, and the superhydrophobicity was restored by heating, verifying a reversible superhydrophobic-superhydrophilic conversion. The influence of voltage, temperature, and time on the coating wettability and its durability under reversible conversion have been studied.
\end{abstract}

\section{Introduction}

Surfaces that are capable of reversibly switchable wettability have attracted increasing interest, especially those able to switch between superhydrophobicity and superhydrophilicity, and hence, the effects of external stimuli on surface wettability have been explored extensively. For instance, chemical valves and sensors may exhibit an excellent wettability responsiveness to external physical and chemical stimuli [1-3]. Stimuli can be divided into: light [4-11], temperature [12-15], $\mathrm{pH}$ [16-18], and electric field [19-25] stimulation.
Zhang et al. [4] reported that superhydrophobic titanium dioxide surfaces become hydrophilic with a contact angle of $0^{\circ}$ after $240 \mathrm{~min}$ of ultraviolet radiation. Nishimoto et al. [5] developed a method for converting superhydrophobic surfaces into superhydrophilic surfaces after only $10 \mathrm{~min}$ of ultraviolet irradiation. Gao et al. [6] prepared 18 alkyltrichlorosilane-modified $\mathrm{TiO}_{2}$ films for the reversible switching between superhydrophilicity and superhydrophobicity of a wood surface. Feng et al. [7] deposited thin films of titanium dioxide nanorods on 
glass substrates by a low-temperature hydrothermal method. The films were stored in the dark for two weeks to yield films with a contact angle of $154 \pm 1.3^{\circ}$. Film irradiation with ultraviolet light for $2 \mathrm{~h}$ rendered the films superhydrophilic with a contact angle of $0^{\circ}$. Li et al. [8] prepared a superhydrophobic and superhydrophilic zinc oxide film on a bamboo surface. The surface was irradiated by ultraviolet radiation/darkroom for $12 \mathrm{~h}$. A storage period of ten days induced the reversible switching between superhydrophilicity and superhydrophobicity. Yang et al. [9] described a simple method for preparing superhydrophobic films using carbon nanotubes. The method did not require chemical modification of the coating. The reversible switching from superhydrophobicity (contact angle of $155^{\circ}$ ) to superhydrophilicity (contact angle of $0^{\circ}$ ) can be achieved by ultraviolet irradiation for $40 \mathrm{~min}$ and darkroom storage for $24 \mathrm{~h}$. Su et al. [10] described the superhydrophobic and superhydrophilic conversion of a bismuth coating. Superhydrophobic and superhydrophilic surface wettability can be achieved by modification of the bismuth coating by ultraviolet light irradiation for $50 \mathrm{~min}$ and exposure to an ethanol solution that contains stearic acid for $3 \mathrm{~min}$. Gu et al. [11] found a way to control the photoinduction of N-12 alkyl mercaptan. It took only $25 \mathrm{~min}$ to change from superhydrophobic (contact angle of about $159 \pm 1^{\circ}$ ) to superhydrophilic (contact angle of $0^{\circ}$ ), and the reverse process took only $30 \mathrm{~s}$.

Esmeryan et al. [12] revealed collapsed superhydrophobicity and conversion to superhydrophilicity upon thermal annealing of the coating at temperatures above $300^{\circ} \mathrm{C}$. Lai et al. [13] prepared a uniform and stable $\mathrm{TiO}_{2}$-based nanoband film by electrophoretic deposition. The transformation of hydrogen titanate to porous $\mathrm{TiO}_{2}(\mathrm{~B})$ and anatase-type $\mathrm{TiO}_{2}$ completed the superhydrophilic-superhydrophobic transition but the process was unidirectional and irreversible. Jiang et al. [14] prepared cotton fabrics by a three-step method that comprised cotton fabrics that were modified by (3-aminopropyl)triethoxysilane (APS) and ( $1 H, 1 H, 2 H, 2 H$-perfluorodecyl)triethoxysilane (PFDTS) at appropriate ratios. The wettability of the cotton fabric could be changed between superhydrophilic (contact angle of $0^{\circ}$ ) and superhydrophobic $\left(161.3^{\circ}\right.$ contact angle) by controlling the temperature to $25-60^{\circ} \mathrm{C}$. Hou et al. [15] studied the influence of drying temperature on the hydrophobicity of $\mathrm{PS} / \mathrm{TiO}_{2}$. By increasing the drying temperature from $20^{\circ} \mathrm{C}$ to $180^{\circ} \mathrm{C}$, the static contact angle of the coating changed from $0 \pm 2^{\circ}$ to $158 \pm 2^{\circ}$.

$\mathrm{Yu}$ et al. [16] prepared a surface with $\mathrm{pH}$ responsiveness that was superhydrophobic in acidic and neutral water but superhydrophilic in an ordinary environment. Lei et al. [17] reported pH-responsive switching between superhydrophobicity and superhydrophilicity for high oil-water separation efficiency. Lv et al. [18] achieved a reversible transformation between superhydrophobicity and superhydrophilicity using a folded graphene coating that was prepared by ethanol drying and prewetting.

The wettability of droplets on electrodes coated with an insulator thin film can be changed by applying direct or alternatingcurrent potentials. This phenomenon is termed electrowetting [19]. The equilibrium morphology under electrical wetting conditions is determined by the equilibrium of Maxwell stress and Laplace pressure [20,21]. Verplanck et al. [22] reported the reversible electrical wetting of droplets on superhydrophobic silicon nanowires in air and oil environments. At $150 \mathrm{~V}$, the maximum contact angle could be reduced by $23^{\circ}$ by electrical wetting in a reversible manner. Li et al. [23] studied the diffusion of droplets of ionic liquids on an insulating electrode subjected to an external voltage. The catalytic effect of a vertical electric field on the reversible transition of graphene surface water droplets from hydrophobic to hydrophilic was studied at a shutdown voltage [24]. Nbelayim et al. [25] achieved the reversible transformation of graphene from hydrophobic to hydrophilic driven by a direct-current voltage. Cui et al. [26] tested droplets of different sizes using a voltage of $3 \mathrm{~V}$ and a $25 \mathrm{~V}$ electrical wetting. The maximum contact angle decreased from $150 \pm 0.1^{\circ}$ to $20^{\circ}$ and the contact-angle saturation conditions changed with droplet size. Zahiri et al. [27] reported the reversible active control of surface wettability of copper electrodeposition by an electrochemical process. The surface wettability could be controlled from superhydrophobic to superhydrophilic. When the sample was dried at room temperature or heated at $100{ }^{\circ} \mathrm{C}$, the wettability could be reversed.

Compared with the electrowetting phenomenon caused by electric-field-driven solid-liquid interfacial charges, we discovered a phenomenon where the charge is injected and accumulates on the solid surface driven by a direct-current electric field and results in a sharp increase in wettability. In this study, a $\mathrm{SiO}_{2}$ nanoparticle coating sprayed on a glass slide was placed in a high-voltage electric field between two electrodes. The charge was injected through the electrodes and accumulated on the coating by controlling the voltage, temperature, and time. The surface wettability of the coating changed from superhydrophobic to superhydrophilic and was restored by heating.

\section{Experimental \\ Materials and instrumentation}

Alcohol (99.7\%, AR) and hydrophobic silica (16-25 nm diameter) was provided by Evonik Degussa Co. Ltd. (Germany). The varnish (Voep-1) was from Shijiazhuang Paint Company. All reagents were used as received without further purification. A high-voltage power supply (Tianjin Dongwen) was used for wettability modification of the silica surfaces. An S3000 scan- 
ning electron microscope (SEM, Japan Hitachi Group) and a Kelvin probe force microscope (Bruker Dimension Icon, Brook) with a SCM-PIT probe (Pt/Ir coated tips, $2.8 \mathrm{~N} / \mathrm{m}, 75 \mathrm{kHz}, \mathrm{Pt} / \mathrm{Ir}$ reflective coating) were used for surface-potential characterization. Atomic force microscopy (AFM) was used to characterize the physical morphology (Bruker Dimension Icon, Brook). The water contact angle (CA) of all surfaces was measured using a JC2000C1 contact angle measurements system (Shanghai Zhongchen Digital equipment). At room temperature, $5 \mu \mathrm{L}$ of deionized water was absorbed by a $5 \mu \mathrm{L}$ needle tube and dripped vertically on the surface of the sample. The final contact angle of the sample surface was the average value of five points on the sample.

\section{Coating preparation}

$0.2 \mathrm{~g}$ of $\mathrm{SiO}_{2}$ was slowly dispersed in $10 \mathrm{~mL}$ of alcohol and sonicated for $30 \mathrm{~min} .1 \mathrm{~mL}$ varnish was added to a mixed solution of $\mathrm{SiO}_{2} /$ alcohol and magnetically stirred for $30 \mathrm{~min}$. The final coating solution was sprayed onto glass slides and cured at room temperature for $2 \mathrm{~h}$ (spraying distance $20 \mathrm{~cm}$, spraying time $3 \mathrm{~s})$.

\section{Experiment setup}

For studying the effect of the DC electric field on the wettability of the coating, an experiment setup as shown in Figure 1a was used. The device was composed of a power supply, electrodes, a heating plate, and a glass slide with a sprayed coating. The coated glass slide was sandwiched between two $\mathrm{Cu}$ electrodes, and half of the slide was treated under an electric field between the electrodes, and the other half was not treated by the electric field, as shown in Figure $1 \mathrm{~b}$.

\section{Results and Discussion \\ Coating morphology and wettability}

The SEM and AFM images of the glass slide before and after the spray coating procedure are shown in Figure $2 \mathrm{a}$ and
Figure $2 b$, respectively. It is obvious that after spraying, the glass-slide surface became rough with a large number of particles that formed irregular micro- and nanoscale composite structures, which increased the roughness of the coating surface and changed the wettability of the coating into superhydrophobic. The surface wettability was inspected and Figure 3 shows that the coating was superhydrophobic with a contact angle of $150.5^{\circ}$. The advancing angle of the layer is $151.2 \pm 0.7^{\circ}$, and the receding angle is $150.2 \pm 0.3^{\circ}$.

\section{Change from superhydrophobic to superhydrophilic in an electric field Effect of voltage on coating wettability}

To evaluate the effect of voltage on the coating wettability, the voltage was changed gradually while the temperature was kept at $150{ }^{\circ} \mathrm{C}$ for $2 \mathrm{~min}$. The results are shown in Figure 4. When the voltage increased from $100 \mathrm{~V}$ to $1200 \mathrm{~V}$, the contact angle remained unchanged at $150.5^{\circ}$. As the voltage increased to $1600 \mathrm{~V}$, the contact angle decreased sharply to $20^{\circ}$. When the voltage increased to $2000 \mathrm{~V}$, the contact angle decreased to $8.1^{\circ}$ and the coating became superhydrophilic, as shown in Figure 5. The electrode contact area of the coating became superhydrophilic but the uncontacted area remained superhydrophobic, as shown in Figure 6.

We examined the morphology of the electrode contact area in the coating by SEM and AFM, as shown in Figure 7. There was no obvious morphology change in electrode contact area compared with the electrode non-contact area (compared to Figure 2b). Therefore, we conclude that the change in coating wettability was not induced by the surface morphology. To establish the reason for the wettability change, Kelvin probe force microscopy was used to detect the surface potential of the electrode contact area and the electrode non-contact area in the coating. The surface potential was measured at five points in each sample area. The results are shown in Table 1.

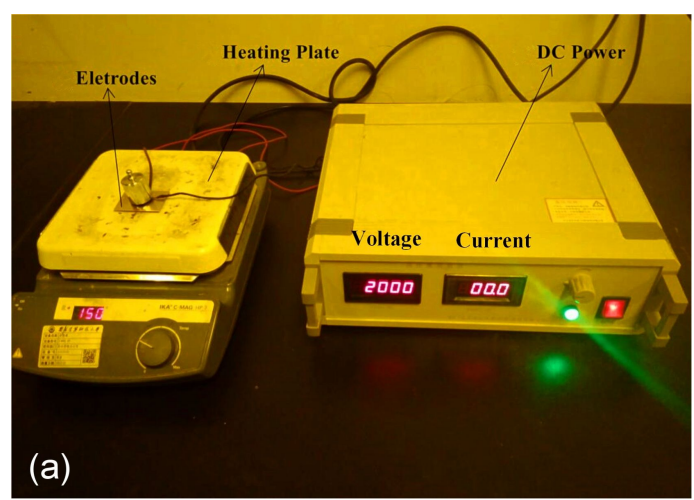

Figure 1: Images of the experimental device for charging

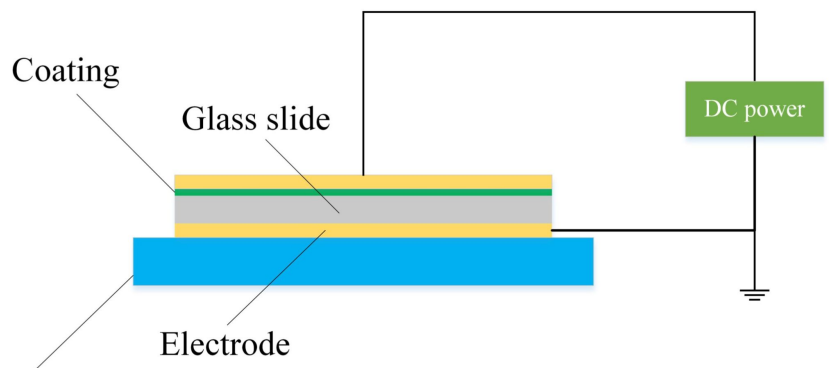

Heating plate

(b) 

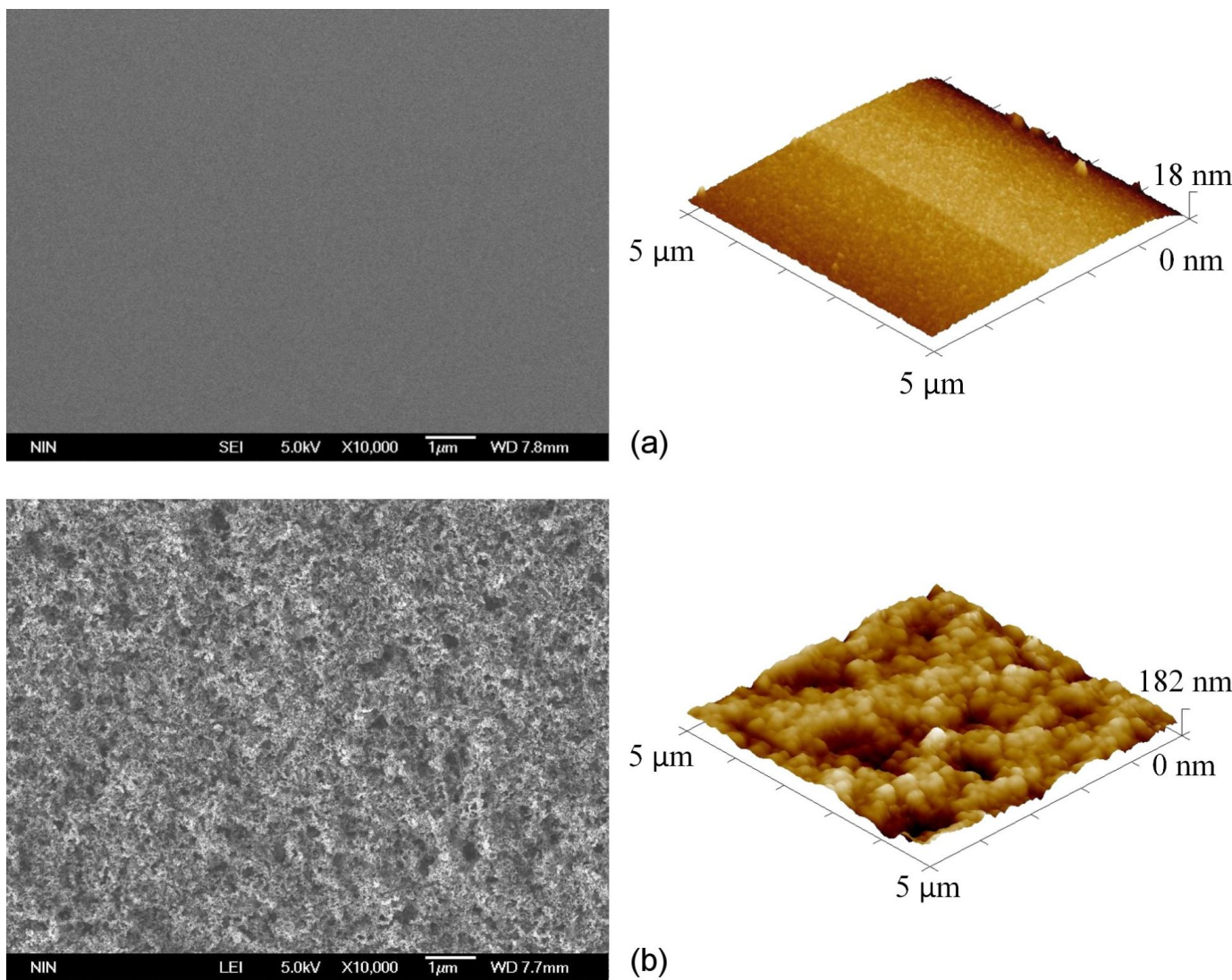

(a)

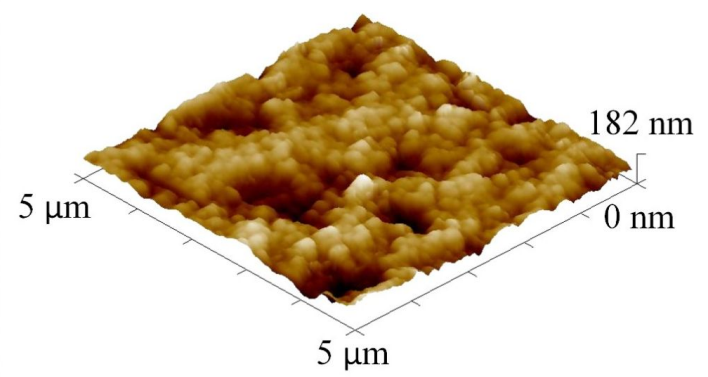

(b)

Figure 2: SEM and AFM images of a glass slide a) before and b) after the spray coating procedure.

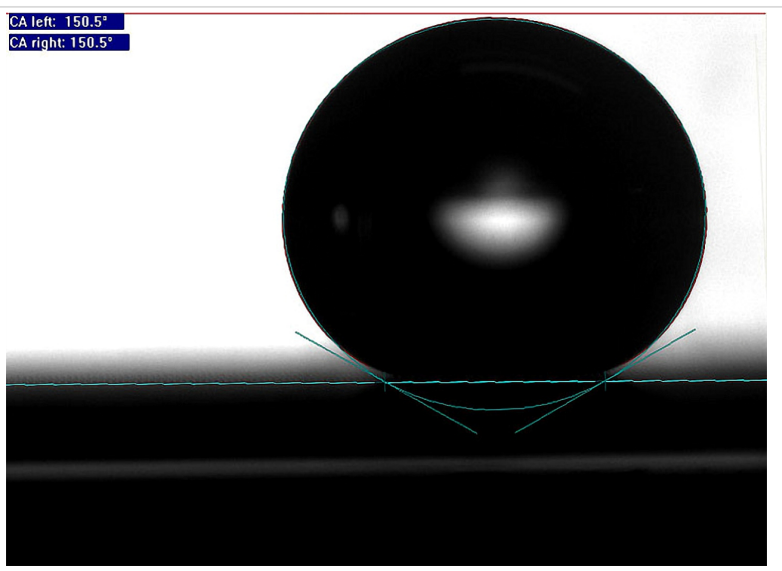

Figure 3: Contact angle of water on the sprayed coating, before charging.

Because there are many KPFM images (CPD) for the whole data set in Table 1, as an example, we have only shown the KPFM image for the point 1 to show the contact potential difference, as shown in the Figure 8.

As shown in Table 1 and Figure 8, the surface potential in the electrode non-contact area showed significant fluctuations

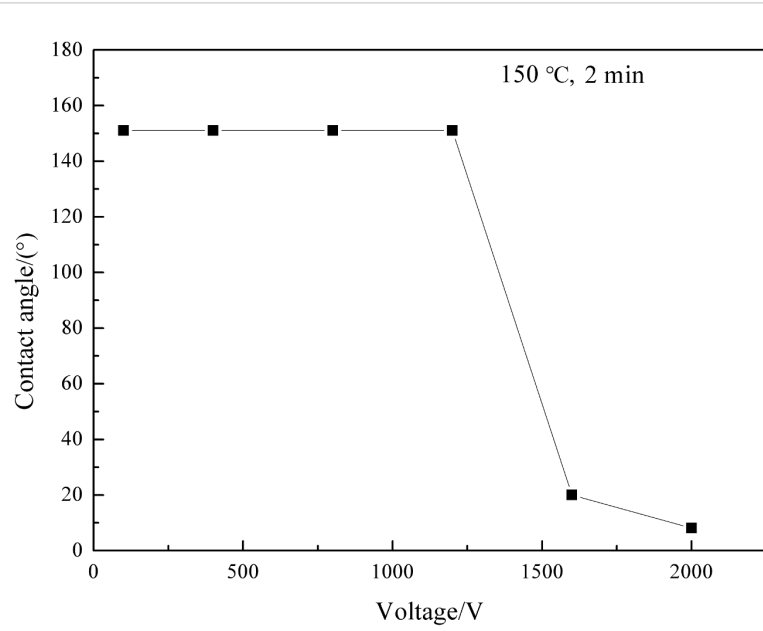

Figure 4: Changes in the contact angle as a function of voltage for the coating $\left(T=150^{\circ} \mathrm{C}, t=2 \mathrm{~min}\right)$.

$(0.07-1.29 \mathrm{~V})$. However, the surface potential in the electrode contact area remained almost constant $(-0.25 \mathrm{~V}$ to $-0.24 \mathrm{~V})$. According to the basic principle of Kelvin probe force microscopy, in the uncharged area, the surface potentials fluctuate significantly and result in random data, whereas in the charged 


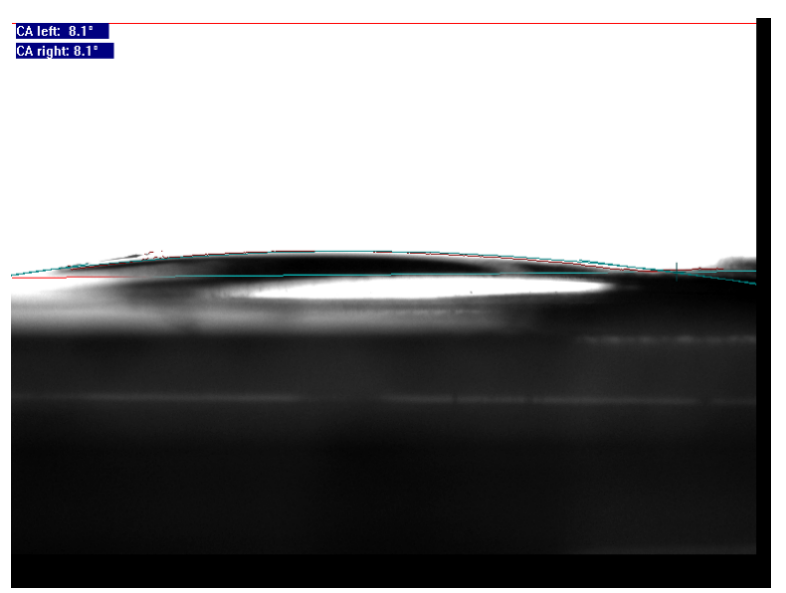

Figure 5: Contact angle of the coating after charging for 2 min at 2000

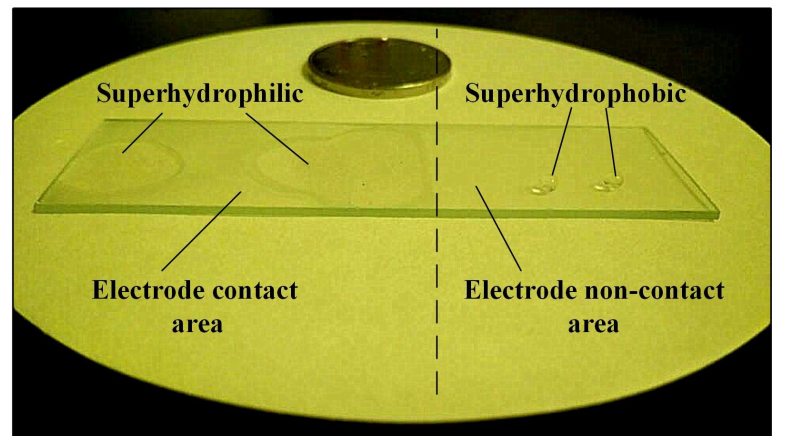

Figure 6: Contrast in wettability of the electrode contact area (afte charging for $2 \mathrm{~min}$ at $2000 \mathrm{~V}$ ) and the non-contacted area for the same coating/sample.

area, the surface potentials remain steady. As we have known, the electrowetting phenomenon caused by electric-field-driven solid-liquid interfacial charges will change the wettability from
Table 1: Electrical potential of points within the electrode contact after charging for $2 \mathrm{~min}$ at $2000 \mathrm{~V}$ and points within the non-contact area.

\begin{tabular}{lll} 
Position & $\begin{array}{l}\text { Electrode contact } \\
\text { area/V }\end{array}$ & $\begin{array}{l}\text { Electrode } \\
\text { non-contact area/V }\end{array}$ \\
\hline point 1 & -0.24 & 0.89 \\
point 2 & -0.25 & 1.29 \\
point 3 & -0.24 & 0.61 \\
point 4 & -0.25 & 0.07 \\
point 5 & -0.25 & 0.22 \\
average value & -0.25 & 0.61
\end{tabular}

hydrophobic to very hydrophilic [19-27]. We thought that the charges injected and accumulated on the solid surface by a direct-current electric field may also change the surface wettability. For example, the charges that were injected in the electrode contact area converted the coating wettability from superhydrophobic to superhydrophilic. Moreover, only when the voltage is high enough, the charges injected into the solid surface will be enough to change the coating wettability from superhydrophobic to superhydrophilic.

\section{Influence of temperature on coating wettability}

To evaluate the effect of heating temperature on the coating wettability, the temperature was changed gradually while the voltage was kept at $2000 \mathrm{~V}$ and the charging time was kept at 2 min, and the results are shown in Figure 9. At room temperature, the coating contact angle remained at $150.5^{\circ}$. When the coating was heated at $50{ }^{\circ} \mathrm{C}$, the coating wettability changed from superhydrophobic to weak hydrophilic (from $150.5^{\circ}$ to $\approx 40^{\circ}$ ). At $100{ }^{\circ} \mathrm{C}$, the contact angle of the coating decreased to $\approx 20^{\circ}$. As the temperature increased to $150{ }^{\circ} \mathrm{C}$, the coating wettability changed to superhydrophilic. The contact angle remained unchanged when the temperature exceeded $150{ }^{\circ} \mathrm{C}$, and the coating wettability remained superhydrophilic. We
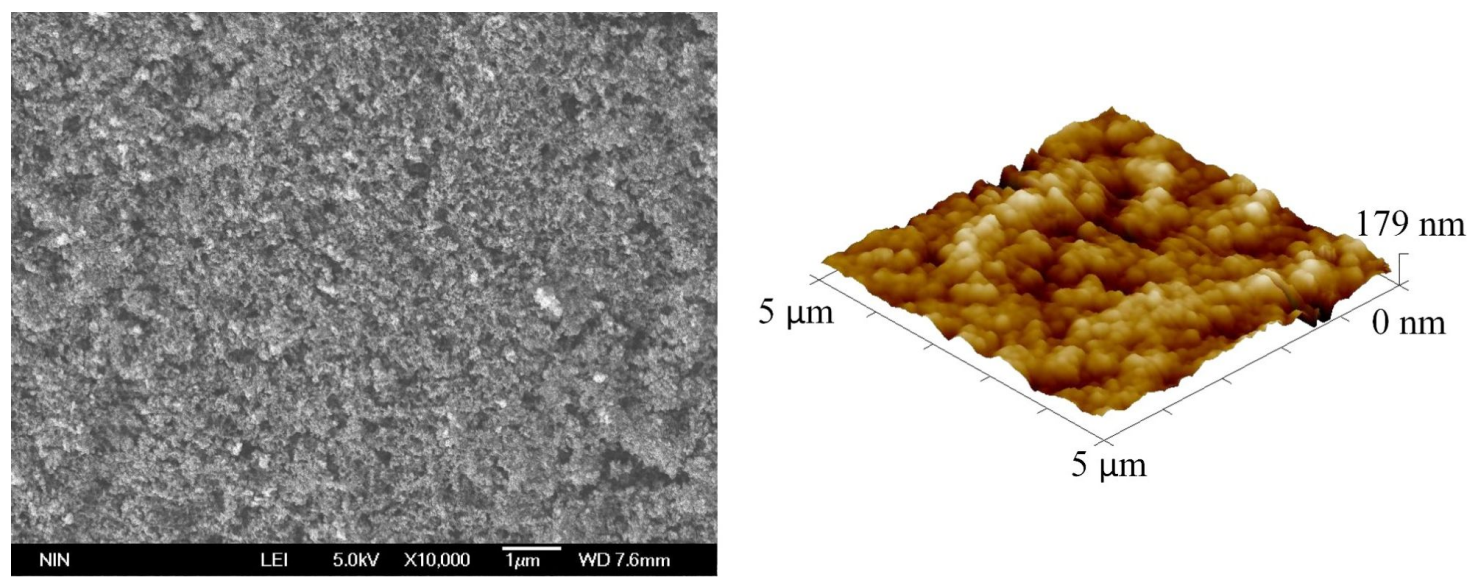

Figure 7: SEM and AFM image of the electrode contact area (after charging for 2 min at $2000 \mathrm{~V}$ ) in the coating. 


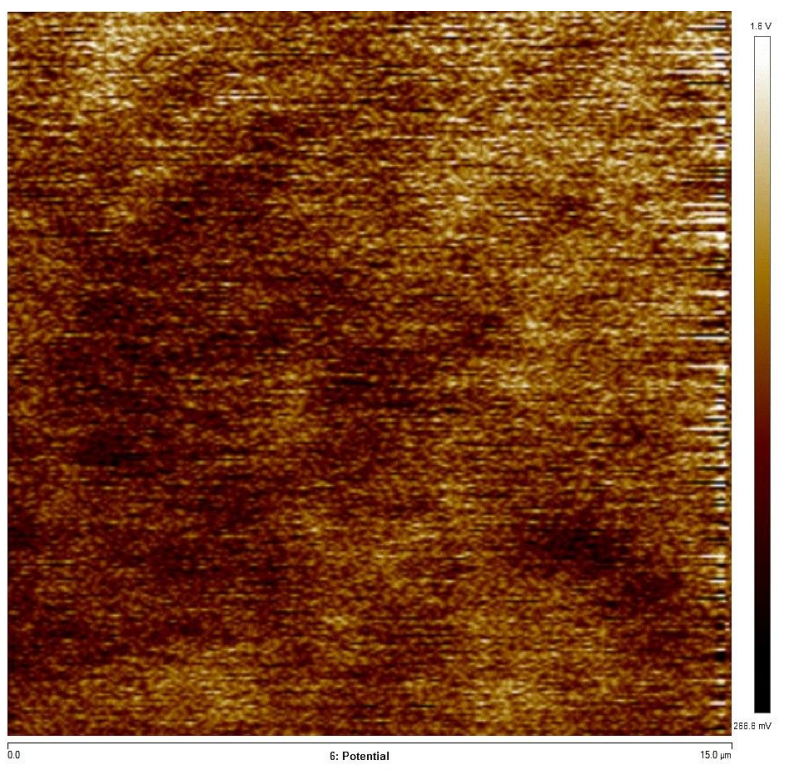

(a)

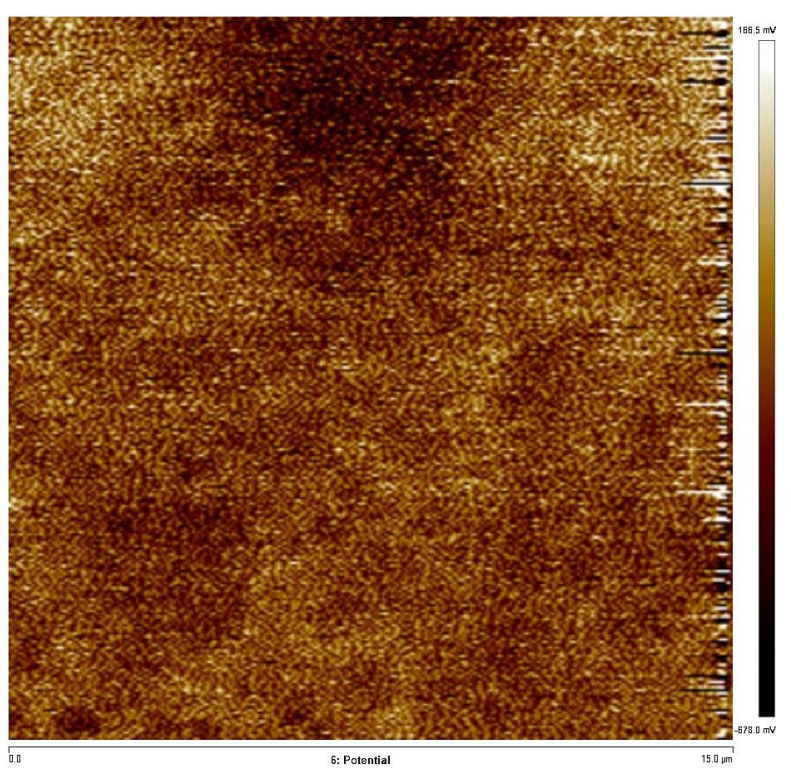

(b)

Figure 8: Potential distribution of point 1: a) electrode non-contact area and b) electrode contact area.

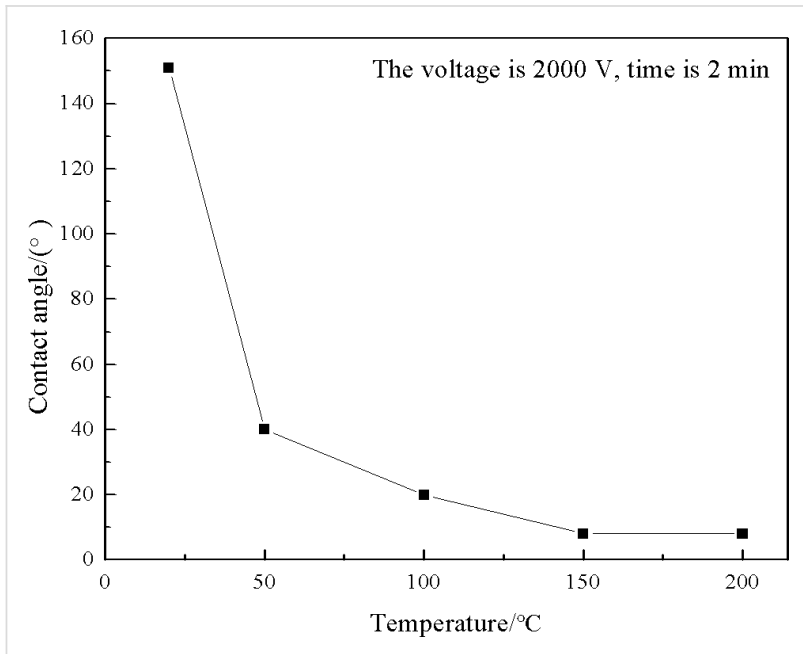

Figure 9: Changes in the contact angle of the coating upon heating (2000 V, $2 \mathrm{~min})$.

speculated that the reason for the enhanced wettability transition from superhydrophobic to superhydrophilic with increasing temperature may be the following: the increase of temperature will promote the thermal motion of the molecules in the solid, which in turn will help the charges inject into the solid surface during the process of electric field application.

\section{Effect of charging time on durability of superhydrophilicity}

When the charging time is too short, the coating wettability cannot change from its original state (superhydrophobic) to superhydrophilic. For example, at $2000 \mathrm{~V}$ and $150{ }^{\circ} \mathrm{C}$, the contact angle of the coating changed from $150.5^{\circ}$ to $40^{\circ}$ after $1 \mathrm{~min}$. Only when the charging time is increased, such as at 2 min, will the coating achieve superhydrophilicity. The durability of the obtained superhydrophilicity of the coating varied with charging time. These results are presented in Figure 10.

Figure 10 shows that the original superhydrophobic coating charged for 2 min became superhydrophilic and the coating remained superhydrophilic after storage for 1 day at room temperature. However, after 2 days and 10 days at room tempera-

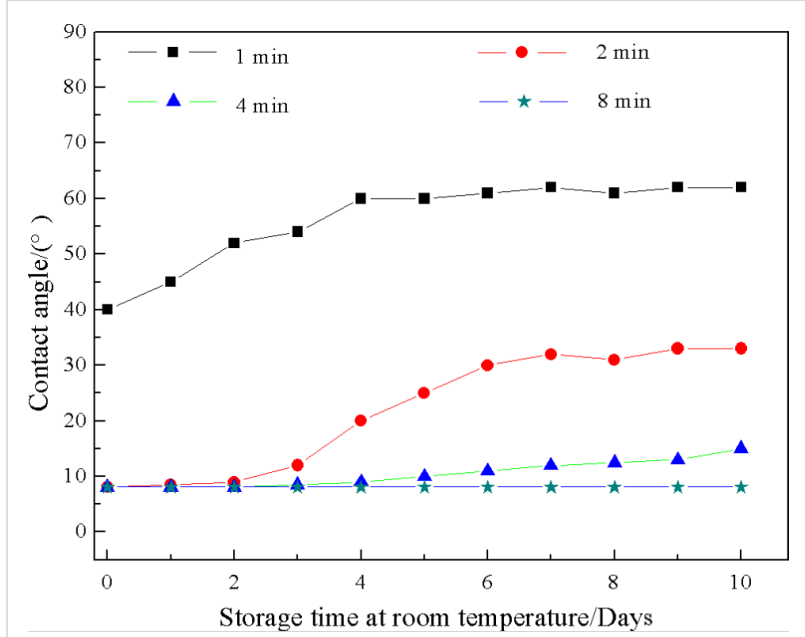

Figure 10: Changes in contact angle of the coating as a function of storage time for four charging times at $2000 \mathrm{~V}$ and $150^{\circ} \mathrm{C}$. 
ture, the contact angle of the coating increased to $9^{\circ}$ and $33^{\circ}$, respectively. The contact angle of the coating charged for $4 \mathrm{~min}$ also increased gradually at room temperature and the highest contact angle could be restored to $15^{\circ}$ after 10 days. After 10 days at room temperature, the surface wettability of the coating charged for $8 \mathrm{~min}$ remained superhydrophilic. From the above results, it is obvious that the durability of superhydrophilicity increased with increasing charging time. We speculate the reason is that more charges will be injected into the solid surface when the charging time is longer, which in turn will increase the durability of superhydrophilicity.

\section{Recovery from superhydrophilicity to superhy- drophobicity with heating}

Heating treatment was used to restore the coating wettability from superhydrophilicity to superhydrophobicity. For example, a superhydrophilic coating was obtained by charging at $2000 \mathrm{~V}$ and $150{ }^{\circ} \mathrm{C}$ for $2 \mathrm{~min}$. The superhydrophilic coating was treated at different heating temperatures and heating times, and the results are shown in Table 2.

\begin{tabular}{|c|c|c|}
\hline $\begin{array}{l}\text { Heating } \\
\text { temperature } /{ }^{\circ} \mathrm{C}\end{array}$ & Heating time & Final contact angle $/^{\circ}$ \\
\hline room temperature & $10 \mathrm{~d}$ & 33 \\
\hline 100 & $48 \mathrm{~h}$ & 90 \\
\hline 150 & $5 \mathrm{~h}$ & 150.5 \\
\hline 200 & $40 \min$ & 150.5 \\
\hline 300 & $10 \mathrm{~min}$ & 150.5 \\
\hline
\end{tabular}

After storing at room temperature for 10 days, the contact angle of the superhydrophilic coating changed to $33^{\circ}$. At a heating temperature of $100{ }^{\circ} \mathrm{C}$, the contact angle of the superhydrophilic coating increased to $90^{\circ}$ after $48 \mathrm{~h}$. At a heating temperature of $150{ }^{\circ} \mathrm{C}$, the contact angle of the superhydrophilic coating increased to $150.5^{\circ}$ after $5 \mathrm{~h}$. After heating at $200{ }^{\circ} \mathrm{C}$ for $40 \mathrm{~min}$, the superhydrophilic coating recovered its superhydrophobicity (from $8.1^{\circ}$ to $150.5^{\circ}$ ). An increase in heating temperature, for example to $300{ }^{\circ} \mathrm{C}$, results in a shortening of the heating time for the recovery of superhydrophobicity to $10 \mathrm{~min}$.

\section{Reversible conversion of coating superhydrophilicity-superhydrophobicity}

The above discussion indicates that the coating can exhibit a reversible superhydrophobic-superhydrophilic conversion. The details are shown schematically in Figure 11. The surface wettability of the coating changed from superhydrophobic to superhydrophilic under the combined action of an electric field and heating. The surface wettability of the coating recovered from superhydrophilic to superhydrophobic with heating.

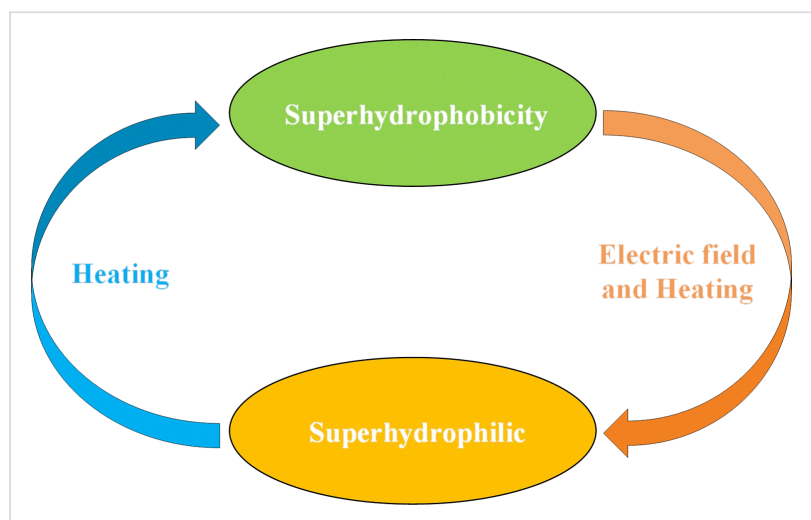

Figure 11: Reversible conversion of coating

superhydrophilicity-superhydrophobicity.

To verify the durability of this reversible process, a superhydrophobic coating was charged at $2000 \mathrm{~V}$ and $150{ }^{\circ} \mathrm{C}$ for $2 \mathrm{~min}$. Then, the obtained superhydrophilic coating was heated at $200{ }^{\circ} \mathrm{C}$ for $40 \mathrm{~min}$ to restore its superhydrophobicity. The process was repeated three times, as shown in Figure 12.

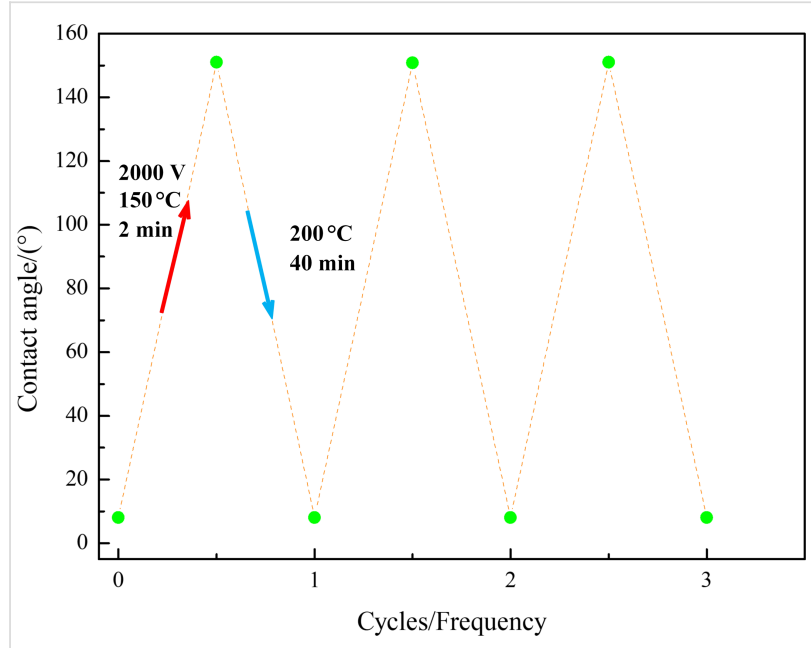

Figure 12: Durability of reversible conversion of coating superhydrophilicity-superhydrophobicity.

\section{Conclusion}

The surface wettability of the initially superhydrophobic, $\mathrm{SiO}_{2}$ nanoparticle, sprayed coating was transformed to superhydrophilic. This switchable wettability was induced by the combined action of an electric field and heating. The application of sufficient voltage, a higher temperature, and a longer charging time resulted in the charge injected on the coating surface, which converted the wettability of the coating from superhydrophobic to superhydrophilic. The coating was shown to re- 
versibly recover from superhydrophilicity to superhydrophobicity with heating.

\section{Acknowledgements}

This work was financially supported by the National Natural Science Foundation of China (Grant Nos. 51475353), the Tribology Science Fund of the State Key Laboratory of Tribology (Grant No. SKLTKF14A02), the Natural Science Basic Research Program of Shaanxi Province (Grant No. 2016JM5004), and the Key Laboratory of the Shaanxi Provincial Department of Education (Grant No. 16JS057, No. 17JS072).

\section{References}

1. Xia, F.; Zhu, Y.; Feng, L.; Jiang, L. Soft Matter 2009, 5, 275-281. doi:10.1039/b803951h

2. Xin, B.; Hao, J. Chem. Soc. Rev. 2010, 39, 769-782. doi:10.1039/b913622c

3. Liu, X.; Liang, Y.; Zhou, F.; Liu, W. Soft Matter 2012, 8, 2070-2086. doi:10.1039/c1sm07003g

4. Zhang, X.; Jin, M.; Liu, Z.; Tryk, D. A.; Nishimoto, S.; Murakami, T.; Fujishima, A. J. Phys. Chem. C 2007, 111, 14521-14529. doi:10.1021/jp0744432

5. Nishimoto, S.; Becchaku, M.; Kameshima, Y.; Shirosaki, Y.; Hayakawa, S.; Osaka, A.; Miyake, M. Thin Solid Films 2014, 558, 221-226. doi:10.1016/j.tsf.2014.02.060

6. Gao, L.; Lu, Y.; Cao, J.; Li, J.; Sun, Q. J. Wood Chem. Technol. 2015, 35, 365-373. doi:10.1080/02773813.2014.984078

7. Feng, X.; Zhai, J.; Jiang, L. Angew. Chem., Int. Ed. 2005, 44, 5115-5118. doi:10.1002/anie.200501337

8. Li, J.; Sun, Q.; Han, S.; Wang, J.; Wang, Z.; Jin, C. Prog. Org. Coat. 2015, 87, 155-160. doi:10.1016/j.porgcoat.2015.05.028

9. Yang, J.; Zhang, Z.; Men, X.; Xu, X.; Zhu, X. Langmuir 2010, 26, 10198-10202. doi:10.1021/la100355n

10. Su, C.; Lu, Z.; Zhao, H.; Yang, H.; Chen, R. Appl. Surf. Sci. 2015, 353, 735-743. doi:10.1016/j.apsusc.2015.06.180

11. Gu, C.; Zhang, J.; Tu, J. J. Colloid Interface Sci. 2010, 352, 573-579. doi:10.1016/j.jcis.2010.08.064

12. Esmeryan, K. D.; Castano, C. E.; Bressler, A. H.; Abolghasemibizaki, M.; Mohammadi, R. Appl. Surf. Sci. 2016, 369, 341-347. doi:10.1016/j.apsusc.2016.02.089

13. Lai, Y.; Tang, Y.; Gong, J.; Gong, D.; Chi, L.; Lin, C.; Chen, Z. J. Mater. Chem. 2012, 22, 7420-7426. doi:10.1039/c2jm16298a

14. Jiang, C.; Wang, Q.; Wang, T. Appl. Surf. Sci. 2012, 258, 4888-4892. doi:10.1016/j.apsusc.2012.01.107

15. Hou, W.; Wang, Q. Langmuir 2009, 25, 6875-6879. doi:10.1021/la900151y

16. Yu, X.; Wang, Z.; Jiang, Y.; Shi, F.; Zhang, X. Adv. Mater. (Weinheim, Ger.) 2005, 17, 1289-1293. doi:10.1002/adma.200401646

17. Lei, Z.; Zhang, G.; Deng, Y.; Wang, C. Appl. Surf. Sci. 2017, 416, 798-804. doi:10.1016/j.apsusc.2017.04.165

18. Lv, L.-B.; Cui, T.-L.; Zhang, B.; Wang, H.-H.; Li, X.-H.; Chen, J.-S. Angew. Chem., Int. Ed. 2015, 54, 15165-15169. doi:10.1002/anie.201507074

19. Hong, J.; Kim, Y. K.; Kang, K. H.; Oh, J. M.; Kang, I. S. Langmuir 2013, 29, 9118-9125. doi:10.1021/la401801u
20. Manukyan, G.; Oh, J. M.; van den Ende, D.; Lammertink, R. G. H.; Mugele, F. Phys. Rev. Lett. 2011, 106, 014501. doi:10.1103/physrevlett.106.014501

21. Esmeryan, K. D.; McHale, G.; Trabi, C. L.; Geraldi, N. R.; Newton, M. I. J. Phys. D: Appl. Phys. 2013, 46, 345307. doi:10.1088/0022-3727/46/34/345307

22. Verplanck, N.; Galopin, E.; Camart, J.-C.; Thomy, V.; Coffinier, Y.; Boukherroub, R. Nano Lett. 2007, 7, 813-817. doi:10.1021/nl062606c

23. Li, H.; Paneru, M.; Sedev, R.; Ralston, J. Langmuir 2013, 29 , 2631-2639. doi:10.1021/la304088t

24. Jiang, Q. G.; Ao, Z. M.; Chu, D. W.; Jiang, Q. J. Phys. Chem. C 2012, 116, 19321-19326. doi:10.1021/jp3050466

25. Nbelayim, P.; Sakamoto, H.; Kawamura, G.; Muto, H.; Matsuda, A. Thin Solid Films 2017, 636, 273-282. doi:10.1016/j.tsf.2017.06.019

26. Cui, W.; Ma, H.; Tian, B.; Ji, Y.; Su, F. J. Mater. Sci. 2016, 51, 4031-4036. doi:10.1007/s10853-016-9721-1

27. Zahiri, B.; Sow, P. K.; Kung, C. H.; Mérida, W. Adv. Mater. Interfaces 2017, 4, 1700121. doi:10.1002/admi.201700121

\section{License and Terms}

This is an Open Access article under the terms of the Creative Commons Attribution License (http://creativecommons.org/licenses/by/4.0). Please note that the reuse, redistribution and reproduction in particular requires that the authors and source are credited.

The license is subject to the Beilstein Journal of

Nanotechnology terms and conditions:

(https://www.beilstein-journals.org/bjnano)

The definitive version of this article is the electronic one which can be found at: doi:10.3762/bjnano.10.84 